\title{
Research on the Operation Mode and Development Countermeasures of University Sports Venues
}

\author{
Wenbo Xuan*; HengWang \\ Department of Physical Education, TianJin Agricultural University \\ TianJin, 300384, China \\ *Corresponding author
}

\begin{abstract}
With the continuous development of China's economic construction, the construction of college sports venues has gradually gained the attention of all sectors of society. As the basic sports facilities for sports development and the development of the city complement each other, through the research on the construction and management of sports venues in Chinese universities, we can find out corresponding solutions to the problems existing in them. Sports venues tend to be more modern and market-oriented with the development of society. Therefore, the management of sports venues should be strengthened as soon as possible, so that the role of sports venues can be better played. Through the analysis of the significance of the operation and management of sports venues in colleges and universities in China, combined with the development status of sports stadiums in China, some reasonable suggestions for the development of sports venues are proposed.
\end{abstract}

Keywords-Operation mode; Development countermeasures; University sports venues

\section{INTRODUCTION}

As a major position to promote national culture, colleges and universities have great responsibilities. As an important part of culture, sports have a great influence on the concept, belief and spiritual appeal of a nation. The development of sports in colleges and universities is to cater to the needs of the times and society, to complement and improve the higher physical education system, and to be the social responsibility of colleges and universities. As one of the important higher education bases in China, Shaanxi Province has a total of 79 colleges and universities, and its stadium resources are abundant. It is the responsibility and obligation of college sports venues to serve the society. It is not the opening of simple sports venues, but the maximum and the service functions of sports venues. It has profound meaning to society, community and family.

\section{CURRENT MANAGEMENT MODE OF COLLEGE SPORTS VENUES}

At present, there are four business management modes open to colleges and universities, which are independent management of colleges and universities, universities and communities, sports companies, and professional companies contracting leasing management and entrusted management. The advantages of self-management and management of colleges and universities are that they have clear division of labor and can be responsible to people. It is conducive to the full use, maintenance and maintenance of college sports venues. It can continuously improve service quality and has strong public welfare. The disadvantage is that the management objectives are not clear. Lack of motivation, employees' enthusiasm for work is not high, and "depending on, wanting, relying on" and other dependent ideas are more serious. The advantage of co-management type is that it can realize the complementary advantages of colleges and universities and sports companies, mutual benefit and win-win, which can disperse risks and achieve scale benefits. The disadvantage is that the responsibilities of both parties are not clear in the management process, management is difficult, and economic benefits are difficult. Maximize implementation. The advantage of the contract leasing business model is that the sports management department of the university has fixed income and is easy to manage. It can improve the use rate of the venue and disperse the business risk in a timely manner. The disadvantage is that the management and management behavior of the contractor and the leasing party are difficult to control, and the contracting period may be The venue is overused, the short-term behavior is serious and the colleges and universities have lower returns. Entrusted management and management can enable colleges to avoid risks and stable income. Both parties have clear responsibilities and can achieve mutual benefit and win-win. At the same time, college sports departments can concentrate on investing in college physical education and successfully complete teaching tasks. The shortcomings are mainly due to the lack of autonomy of colleges and universities. Right, it is difficult to control and supervise the business behavior of the trustee, and the income of colleges and universities is low, and it may cause excessive use of the venue.

\section{AdVANTAGES AND DISADVANTAGES IN CHINA'S SPORTS} STADIUMS

China's college gymnasiums have certain advantages in terms of geographical location, policy and material. In terms of geographical location, because China's colleges and universities are all located in the suburbs or urban areas, the transportation near the school is very convenient, and there are not only communities around them. There are also many enterprises and institutions. In terms of policy, in the "Sports Law", China emphasizes the venues and sports equipment that the school should respond to the allocation standards, and it is not allowed to be used for other purposes. In terms of 
materials, China's colleges and universities have more advanced sports equipment and facilities, and have certain financial guarantees. There are plenty of books on sports in the library for sports enthusiasts to check out. In terms of talents, China's colleges and universities have a very professional team of teachers with professional knowledge of sports and teaching experience in physical education. In terms of information technology, the sports department established in higher education institutions can obtain relevant information of the sports world as soon as possible, so as to make comprehensive use of it.

Although the level of stadium facilities in China's colleges and universities is higher than other stadiums, there are still certain problems, such as insufficient funds and imperfect sports facilities. There are many main reasons for these problems. Due to the low funds for sports activities, the facilities of the gymnasium are few, the sports equipment is replaced slowly, and the sports equipment is outdated. Insufficient investment in sports venues seriously affects the quality of sports teaching. At the same time, due to the relatively lack of physical education resources in colleges and universities, physical education cannot satisfy students' desire for sports knowledge. The venue is too small for students to carry out large-scale sports activities. Therefore, the stadiums can not meet the needs of the teachers and students of the school to some extent.

China's professional sports are relatively late, and there is a certain gap between the professional sports management system, operational mechanism, and personnel training in Western countries such as Europe and the United States. Among them, in the development of sports market and the cultivation of management talents, China has just started and has not yet formed a scale. Therefore, the qualified personnel trained can not meet the social needs, which can be confirmed from the fact that the professional management staff of the stadiums is currently inadequate. The management personnel of some colleges and universities in China are still temporary managers or auxiliary managers, which makes the management team unable to meet the needs of the venue market development. The quality level of college sports venue management personnel also needs to be improved. Liu Wenyan and others have shown that although the sports management personnel in Shandong Province have learned through systematic professional knowledge, the overall educational structure is not reasonable and the highly educated talents are scarce. Ji Xiaowei's research shows that the professional background of most managers in domestic sports venues is not venue management, and non-sports and nonmanagement professionals account for a considerable proportion. These phenomena are also the problem of the management team of college sports venues. This will impose certain restrictions on the future layout and operation of the venue. In addition, the economic development in China's regions is uneven. The number, layout and per capita occupancy of sports venues (including colleges and gymnasiums) in the eastern coastal areas are obviously better than those in the western regions. Most of the professional sports stadium management talents are concentrated here, resulting in sports. The imbalance of human capital distribution in the venue management directly leads to the inefficient development of the stadium market, and also limits the coordination and simultaneous development of the venues between the regions. Therefore, in order to develop the market, venues must be equipped with highly educated professional venue management personnel to encourage them to carry out innovative development of stadium management, so as to continuously improve the use rate of college sports venues.

At this stage, most of the domestic cities have built their own "special" sports venues in the process of hosting some large-scale sports events. On the one hand, these venues can undertake the task of the competition, on the other hand, they can be used as landmarks of the city to enhance the city's taste and establish the image of the city. This has formed a huge contrast with the purpose of "saving, practical and environmental protection" in some cities in foreign countries. As a subsystem of society, colleges and universities are inevitably guided and restricted by the social environment. Specifically, in some colleges and universities, with the expansion of school scale and campus area, new stadiums have risen. These new venues have unique styles in design and layout, but they are not practical in the process of opening up to the outside world. The layout of some venue facilities is unreasonable, and the space utilization is insufficient, which reduces the utilization value and causes waste of resources. During the 16th Asian Games and the Asian Paralympic Games, a total of 70 competition venues were opened in Guangzhou, 12 of which were new venues and 58 were rebuilt or expanded. The capital investment in the construction and maintenance of the competition venue was 6.3 billion yuan. Among them, as one of the newly-built competition venues, the Guangzhou Sports Institute Gymnasium, although considering the energy-saving and environmental protection factors in the design, the main building area of the entire stadium floor reached 13,000 square meters, while the internal space was small, resulting in a decrease in space utilization rate; Because the exterior wall is designed with a column, although the skylight is left at the top of the building and diffused reflection is used to introduce light, the overall lighting rate inside the venue is still affected. These largescale, stylishly designed campus sports venues, combined with outdoor supporting projects, will consume huge amounts of energy and manpower during operation, and will incur huge costs in the maintenance and maintenance of equipment. Therefore, while meeting the teaching needs of colleges and universities, if they are not open to the outside world and open up financing channels, most of these venues will be idle, and the colleges will carry heavy economic burdens.

\section{COUNTERMEASURES FOR THE MANAGEMENT AND DEVELOPMENT OF UNIVERSITY SPORTS FACILITIES IN CHINA}

\section{A. Transforming Traditional Management Concepts}

With the continuous advancement of economic construction, it is necessary to rationally change the traditional management concept. Due to the traditional management concept, the development of sports stadiums in China has been restrained to a certain extent. Therefore, the relevant administrative departments in colleges and universities should 
constantly update their management concepts for colleges and universities, and actively adapt to the development of the times, thus adapting to China's modern market economy. The gymnasium can be rewarded through scientific and rational enterprise operation, and the gymnasiums in major universities can gradually make transitions to the social gymnasium, reasonably arrange the opening hours of the gymnasium, and consider opening up to the public for compensation, thus gaining more economic benefits. With social interests. Since the sports equipment in most colleges and gymnasiums in China is relatively sound, under the premise of ensuring the normal development of physical education in colleges and universities, it can be integrated with the social gymnasium to achieve certain economic benefits.

\section{B. Appropriately Improve the Operational Management Level of the Stadium}

China's colleges and universities should take their own situation as the main basis, and introduce a large number of talents in operation and management, and actively strengthen the service staff's service awareness to a certain extent. The stadium not only needs professional management personnel, but also needs to have a certain division of labor and cooperation with the management personnel. Among them, the management personnel of these sports venues can be divided into two categories, which are responsible for business management and professional and technical staff. Through continuous operation and development, the stadium has continuously adapted to the development needs of the economic market and broke the traditional single operation mode. In order to continuously attract management talents into the gymnasium, we should first improve the personnel structure in the stadiums and encourage employees to carry out on-the-job training. Through regular training of relevant stadium management personnel, the professional skills and knowledge of stadium management personnel will be improved, thereby improving the operational management level of Chinese universities. In addition, the corresponding operational management system should be established to further standardize the work behavior of sports operations managers. When large-scale activities are to be held, the number of security personnel and cleaning personnel should be appropriately increased to improve the related logistics of the school. Only by continuously increasing the social experience of college logistics, we will continue to grow the stadium.

Policy, financial security and operation mode innovation In the process of design, construction and operation of university sports venues, the competent departments of the government and universities should establish a special fund system for the operation of sports venues to ensure that the venues are in the process of service teaching and opening up. , keep a good running state. In addition, it is necessary to continuously expand the investment and financing channels of the venues to ensure the normal supply of sports public services.

In the operation of college sports venues, in order to diversify business risks, a social operation model can be adopted. At present, China is still exploring the management mode of large-scale public sports venues jointly invested by the government and enterprises and jointly operated after the game. The shortcoming of this model is that the contradiction between public welfare and commerciality is not easy to handle. The investment and financing structure of the international stadiums is changing from a government-based to a variety of investment and financing structures. This approach is worth learning from. At present, the emerging management model in China also has a commissioned operation and management model--service outsourcing. This model outsources management activities such as cleaning, maintenance, ticketing and business contacts to professional companies, which can effectively improve operational efficiency. Guangzhou Tianhe Sports Center has adopted lease, contracting and entrusted operations for its affiliated facilities and idle land. Introducing external capital management is a good attempt. A survey of small and medium-sized sports venues in Beijing shows that after the Beijing Olympics, all small and medium-sized sports venues in Beijing adopted a self-operated approach, partly using a leasing, entrusting or contracting business model. The channels for funding sources have been broadened, the stadium industry market has been revitalized, and good economic benefits have been achieved.

\section{Enrich the Activities of Sports Venues}

By setting up some sports leagues and increasing sports events, the stadium will be diversified. Continuously promote the function of colleges and universities in China to develop in an integrated direction. Therefore, in the process of establishing a gymnasium, new sports projects that meet the interests of most students should be established. Therefore, sports resources can be fully utilized. In addition, you can also report large-scale sports interactions with some large enterprises and institutions, such as sports games and so on. Colleges and universities can also hold some exhibitions with their own characteristics in the stadiums, and introduce some singers to report concerts in the stadium. In the process of opening up, the gymnasium should enrich its own functions and continuously expand its own activity space, thus solving the problem of single structure of the stadium. The gymnasium is not only used in the physical education of colleges and universities, but it can play the role of an auditorium at a certain time.

\section{Expanding the Financing Channels for College Sports Venues}

Constantly increasing the fundraising of college sports venues and broadening the fund-raising channels of college sports venues can effectively reduce the economic problems caused by the increase in investment. Efforts have made people from all walks of life pay more attention to the sports stadiums in China, and let the society more actively support the sports industry, thus increasing the investment of funds. Many colleges and universities have made great success through hard work. The main ways to raise funds are: joint ventures, joint sponsorships, etc. Only if they have a positive effect on the development of sports in China's colleges and universities, they should work hard. Continuously strengthen the operation and management of sports venues, so that 
stadiums and gymnasiums can better serve students and society.

Team Marketing Promotes Sustainable Development In the process of opening up college sports venues, it is possible to implement marketing methods such as membership cards and unit leasing and group package to stabilize business performance. Try to establish a three-in-one management mode of sports clubs, business clubs and member clubs. At the same time, the theme of college sports venues can be designed as a combination of fashion, health and leisure, that is, the leisure university sports hall management mode is adopted.

The operation of college sports venues should be in line with international standards As the globalization process continues to accelerate, exchanges between countries around the world are becoming more frequent, and the internationalization of colleges and universities has become a trend. As part of the daily work of colleges and universitiesthe operation and management of college sports venues must also face the world and integrate into the tide of globalization. In this process, we must learn from the advanced experience of foreign countries and update the management concept of sports stadiums in China. The United States is the best country in the world for sports and professional sports. The large-scale sports stadiums in the United States have introduced professional sports management companies for human resource management and venue maintenance. The sports stadium professional management company is engaged in the operation and management of local sports facilities. . In addition, some famous international stadium operators such as SIV, AEG, Renault, GSE and SMG in the UK have their own advanced sports hall management concepts and mature operation methods, which are worth learning and learning. Therefore, while strengthening the theoretical study and skill training of university sports stadium managers, we must also continuously strengthen its communication, cooperation and innovation capabilities, and actively establish an operational team with an international vision, as far as possible in the venue management and operation methods.

\section{CONCLUSION}

As an important base for cultivating talents in China, major universities must realize the transformation of the stadium management mode as a whole, and continuously improve the level of management of the stadium, so as to quickly promote the sustainable development of major universities. Through the effective analysis of the current status of the sports stadiums in China, the paper proposes reasonable solutions to the problems of singularity and lag, and promotes the development of colleges and universities in China. Through the analysis of the construction of the gymnasium in colleges and universities, the relevant solutions to the problems arising in the construction process will be taken to continuously expand the fund-raising channels of the university gymnasium, improve the comprehensive operational capacity of the gymnasium, and increase the modernization function of the gymnasium.

\section{ACKNOWLEDGEMENT}

This research was supported by Tianjin Education Commission Scientific Research Plan Project:Research on the operation and management mode of university sports venues in Tianjin during the post National Games.(No.2017SK088).

\section{REFERENCES}

[1] Bi Jinjie. Research on the Current Situation and Countermeasures of University Sports Management in China[J]. Journal of Guangdong Education Institute, 2006(1): 97-100.

[2] $\mathrm{Hu}$ Banghui. Research on the operation management of college sports venues [D]. East China Normal University, 2007.

[3] Yu Feng. Investigation and research on the current situation of sports stadiums in some universities in Shanghai[J].Sports Science Research,2005(2):90-93.

[4] Wen Shiping, Liao Xiaolin, Wang Ruohong. Research on the Construction and Development Trend of University Sports Venues[J]. Journal of Wuhan Institute of Physical Education, 2003(5): 157-158.

[5] Liu Jing, Chen Yuanxin. Status Quo, Characteristics and Development Trend of Sports Venues in Colleges and Universities[J]. Journal of Wuhan Institute of Physical Education, 2010, 44(10): 24-28. 